\title{
Domestic Robot for LPG and AC Gas Leakage Detection
}

\author{
J. Tisa \\ Robotics Lab \\ Malco Vidyalaya Matriculation \\ Higher Secondary School \\ Mettur Dam, Salem District \\ Tamil Nadu, India
}

\author{
J. Lepika \\ Robotics Lab \\ Malco Vidyalaya Matriculation \\ Higher Secondary School \\ Mettur Dam, Salem District \\ Tamil Nadu, India
}

\author{
J. Nedumaan \\ Computer Lab \\ Vedanta Vidyalaya \\ CBSE School \\ Mettur Dam, Salem District \\ Tamil Nadu, India
}

\begin{abstract}
This paper describes the making of a domestic robot for early gas leakage detection particularly in kitchen and bedroom all over the year. The idea behind this invention is to evade any life loss due to AC gas leakage and to detect LPG gas leakage at the earliest to sidestep serious fire accidents saving human lives. The proposed domestic robot detects any suspicious gas leakage within a suggested distance say few meters and raises the alarm. If the alarm is not switched off physically within 5 minutes, the microcontroller starts sending SMS to the registered mobile number every 15 minutes until the alarm is switched off physically. The authors are certain of such domestic robots can protect human lives from household accidents.
\end{abstract}

\section{General Terms}

Air Conditioner (AC), Liquefied Petroleum Gas (LPG), Short Message Service (SMS), Microcontroller

\section{Keywords}

Domestic Robot, Gas Leakage Detection, Solid State Sensors

\section{INTRODUCTION}

Domestic accidents and loss of human lives have become unavoidable. In day to day life, one should come across many domestic calamities in the daily newspapers and magazines due to AC and LPG gas leakage. On $3^{\text {rd }}$ October 2018, a family of three in Chennai lost their lives at sleep after inhaling toxic gas from the air conditioner in their bedroom. This incident took the country to shock including the authors. The authors decided to discover a reasonable and affordable solution in this regard through an indoor domestic robot.

A domestic robot is a kind of administration robot, a selfgoverning robot that is basically utilized for family tasks, however may likewise be utilized for instruction, excitement or treatment [4]. Up to this point, there are just a couple of constrained models; however examiners, for example, Bill Gates, have recommended that they could turn out to be increasingly regular later on. While most residential robots are oversimplified, some are associated with Wi-Fi home systems or savvy situations and are self-governing to a high degree.

Indoor domestic robot does tasks around and inside homes. Various types include: robotic vacuum cleaners and floor washing robots that perfect floors with clearing and wet wiping capacities. Some utilize swiffer or other expendable cleaning materials to dry-clear, or reusable microfiber fabrics to wet-mop. Outdoor domestic robot like grass cutter can trim a garden independent from anyone else subsequent to being modified. Automated grass cutters accompany a power unit which might be an electric engine or inward ignition motor. This gives capacity to the robot and enables it to move itself and its cutting sharp edges [6].

\section{LIQUEFIED PETROLEUM GAS}

Liquefied petroleum gas (LPG) is a monochrome odorless fluid which promptly evaporates into a gas. Regularly an odorant has been added to it to help distinguish leaks. LPG has an exceptionally wide assortment of employments, for the most part utilized for chambers crosswise over a wide range of business sectors as an effective fuel holder in the farming, diversion, accommodation, mechanical, development, cruising and angling divisions [7]. It can fill in as fuel for cooking, focal warming and to water warming and is essentially commercial savvy and productive approach to warm offnetwork homes. LPG is utilized for cooking in numerous nations for monetary reasons, for comfort or in light of the fact that it is the favored fuel source. LPG is made for the most part out of propane and butane; however flammable gas is made out of the lighter methane and ethane. Commercial LPG is primarily derived from fossil fuels.

In India, almost 10 million tons of LPG was expended in the half year in household segment, fundamentally for cooking. The quantity of local associations are 250 million (i.e., one association for each five individuals) with a flow of in excess of 400 million LPG cylinders. The majority of the LPG need is imported. Piped city gas supply in India isn't yet created on real scale [8]. LPG is financed by the Indian government for domestic customers. Raise in LPG costs has been a politically delicate issue in India as it conceivably influences the white collar class casting a ballot. Despite the fact that dangerous, the utilization of LPG for cooking has turned into the most helpful methods in India.

LPG might leak as a gas or a fluid. On the off chance that the fluid leaks, it will rapidly dissipate and form an enormous haze of gas which will drop to the ground, as it is heavier than air. At the point when the gas meets a wellspring of start it can burn or detonate. It is delegated as exceptionally combustible and on the off chance that it has more than $0.1 \%$ Butadiene; it is likewise named as a carcinogen and mutagen. LPG is noncorrosive yet can dissolve lubricants and plastics.

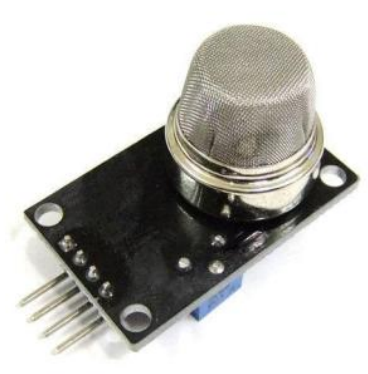

Fig 1: LPG/AC gas leakage sensor unit 


\section{AIR CONDITIONER}

Air conditioning is the way toward expelling warmth and dampness from the inside of a consumed space, to improve the solace of inhabitants. Cooling can be utilized in both local and business situations. This procedure is generally used to achieve an increasingly agreeable inside condition, ordinarily for people and different creatures; be that as it may, cooling is moreover used to cool rooms loaded up with electronic gadgets, for example, PC servers, control intensifiers. The instrument is called Air Conditioner (AC). Air conditioners frequently utilize a fan to appropriate the molded air to a consumed space, e.g., a structure or a vehicle to improve warm solace and indoor air quality. Electric refrigerant-based $\mathrm{AC}$ units run from little units that can cool a little room, which can be conveyed by a solitary grown-up, to enormous units introduced on the top of office towers that can cool a whole structure. The cooling is ordinarily accomplished over a refrigeration cycle; though once in a while evaporation is utilized [8].

An appropriately running air conditioner circulates and keeps up a similar measure of refrigerant. A decrease of refrigerant is definitely not a typical piece of the activity of the $\mathrm{AC}$ and likely flag an AC refrigerant leak. Freon gas leak is regularly brought about by little cut openings that permit the gas-fluid to get away. Freon is surely a wellbeing risk. Freon is a deadly dangerous substance, and hence, freon leaks ought to be dealt with by a specialist cooling repair technician [7]. Breathing in freon is very toxic and could result in death. Furthermore, freon leaks exhaust the ozone layer and are perilous for the earth. The greatest worry with freon leaks is guaranteeing that no freon enters the wind current inside home. The most wellknown reason for $\mathrm{AC}$ freon leaks is likely disintegration of the metal after some time because of formic corrosive or formaldehyde consumption. Little openings are shaped when the corrosive destroys the metal and the unit in the long run discharges freon. This can be fixed by ousting the different parts, for example, the curls or introducing a whole new cooling unit relying upon the seriousness of harm.

Solid state sensors are utilized to recognize both LPG/AC gas leakages in the proposed work as appeared in Fig 1. It utilizes a metal oxide (often tin oxide or aluminum oxide) framed into a shell type sensor [2]. A warming component is utilized to keep the sensor at an ideal temperature for the gas to be identified. LPG/AC gas leakage sensor unit is intended to empower gas recognition interface to microcontroller. It permits deciding when a preset gas level has been come to or surpassed. The locally available microcontroller give initial warming interim after controlled and afterward begins to gauge gas sensor yield. In the event that it found the gas substance above proposed esteem, it will educate the host controller by dismantling the yield stick to high and begins to squint a locally available status LED. The sensor module is chiefly expected to give a method for contrasting gas leakage sources and having the option to set a caution limit when the source ends up over the top [3]. Solid state sensors distinguish leaks by detecting changes in conductivity; a couple of onesided anodes are implanted into the sensor to gauge the conductivity change. At the point when the sensor interacts with gas getting away from a release, that gas is adsorbed onto the sensor surface, changing the opposition of the sensor material. Now, when the gas evaporates, the sensor comes back to its unique condition. What makes solid state sensors particularly useful for discovering gas spills is the indication they produce, which increments within the sight of high gas fixations. Solid state sensors are exceptionally adaptable.
They identify both low and high convergences of gas and can be redone to recognize a wide range of gases by changing the sensor's materials, and working temperature. The essential quality of solid state sensors is their long life [5]. In clean conditions, the sensor can last as long as 15 years, vividly longer than other sensor types. This is a major bit of leeway for an apparatus that is utilized just discontinuously (except if you have a great deal of gas leaks!).

\section{MAKING OF DOMESTIC ROBOT}

The advance of the robot began with two central objectives. Right off the bat, the item ought to be hassle free, and also, it ought to be efficient. With these points in front, the materials are picked and configuration was made. The principle body of the robot is round and hollow fit as a fiddle with a width of $375 \mathrm{~mm}$ and is made of tin sheet of thickness $1 \mathrm{~mm}$ along the edges and top and base are made of acrylic plates of thickness $3 \mathrm{~mm}$ [8]. The base was strengthened by a $375 \times 75 \times 4 \mathrm{~mm} 3$ aluminum plates to support the loads of the hardware inside. The robot is about $250 \mathrm{~mm}$ high from the beginning. The vitality wellspring of the robot is an upkeep free fixed lead corrosive battery with a rating of $7.2 \mathrm{Ah}$ and voltage of $12 \mathrm{~V}$, as all the electrical gear utilized inside require $12 \mathrm{~V}$ to run [1]. A microcontroller is utilized to run the control program and to control the activity arrangement. Microcontroller is a broadly useful gadget having enormous number of the segments of a microchip framework on a solitary chip. At the present time, assortments of microcontrollers are accessible in a market. Here, ATMEL AT89S51 is utilized. It has 128 bytes of RAM, $4 \mathrm{~K}$ bytes of on-chip ROM, perfect with MCS-51 items, 32 programmable I/O Lines, Programmable Serial Channel, Six intrude on sources, low-control inert and shut down modes.

LPG/AC gas leakage sensor is utilized for recognition of hazardous gases. The yield of this sensor is simple structure. Following the concentration of gas at outside condition in PPM (parts per million), the output of the sensor changes from 0 to $5 \mathrm{~V}$. In ordinary conditions, yield of this sensor is $12 \mathrm{mV}$. The yield of this sensor is nourished into analog to digital converter unit which is additionally prepared into advanced structure before passing it to microcontroller unit. Convergence of gas in air is evaluated by the microcontroller program.

\section{Gas Leakage Detection: Program}

The sensor is coupled to A0 pin. The voltage recited from the sensor is revealed. This value can be employed as an onset to sense any upsurge/reduction in gas concentration.

void setup ( )

\{

Serial.begin (9600);

\}

void loop ( )

\{

float sensor_volt;

float sensorValue;

sensorValue $=$ analogRead $(\mathrm{A} 0)$;

sensor_volt $=$ sensorValue/1024*5.0;

Serial.print ("sensor_volt = ");

Serial.print (sensor_volt); 
Serial.println ("V");

delay (1000);

\section{WORKING OF DOMESTIC ROBOT}

The working of the planned robot is simple and user friendly. The entire robot is built on the acrylic sheet. Acrylic sheet is utilized for the assembling the base for robot on account of novel properties like light weight, more effect obstruction, increasingly adaptable, amazing protection from synthetic compounds, protector, and climatic conditions. The robot is designed to work both with both commercial power supply and battery as well. Once the robot gets the power supply, the microcontroller starts functioning according to the basic functions programmed. The basic program for gas leakage detection is shown above.

The domestic robot uses the solid state sensor to sense any LPG/AC gas leakage within 25 to 30 feet. As mentioned, the solid state sensors are of high sensitivity in detecting gas leakage. The output voltage from the gas sensor increases when the concentration of gas increases. Sensitivity can be adjusted accordingly. The best preheat time for the sensor is above 24 hours. The concentration of few gases is explained in Fig 2 and Fig 3.

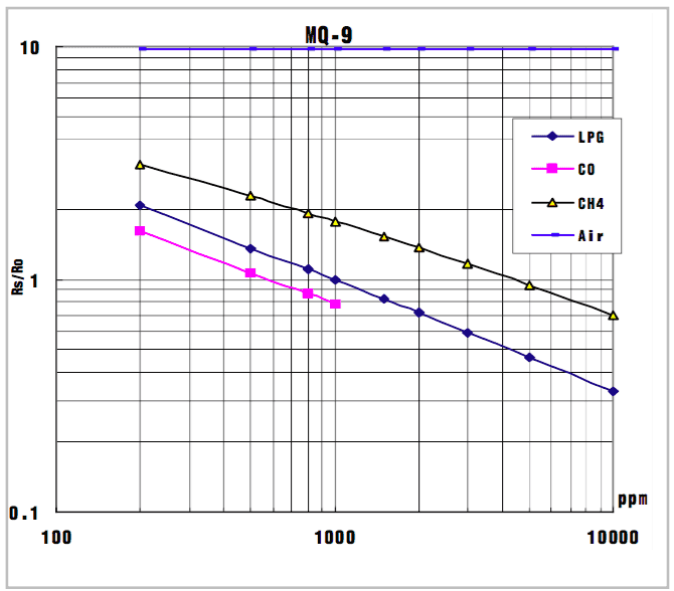

Fig 2: Concentration of Air, LPG, CO and CH4

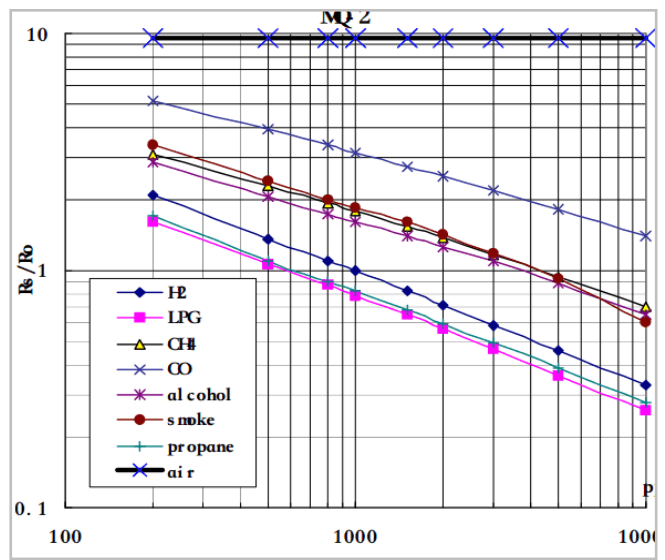

Fig 3: Concentration of Air, LPG, CO, CH4, Smoke, Alcohol, HE, Propane

If the robot detects any suspicious gas leakage, it raises the alarm. If the alarm is not switched off substantially within 5 minutes, the microcontroller starts mentioning SMS to the registered mobile number every 15 minutes until the alarm is switched off physically.

\section{OBSERVATION AND CONCLUSION}

It is observed that both the sensor unit and SMS unit are very well interfaced with the microcontroller via $\mathrm{Wi}-\mathrm{Fi}$ connection. The robot works fine in normal conditions in detecting the gas leakage but with high level of smoke in the kitchen the sensor starts flickering causing error. Even during fire and fire accidents due to high smoke, the robot malfunctions. It is experimental that under normal conditions, the robot is $96 \%$ well-organized. As a future direction, the robot can be further modified in sensing electricity leakage to avoid fire accidents in saving human lives. Compared to the cost of AC and commercial LPG, the cost of the proposed robot is cheap and affordable. The most important point is it warns any serious accidents in protecting the valuable human life. The proposed robot is not mobile and can be converted into a portable robot depending upon the situation and application.

\section{ACKNOWLEDGMENTS}

Our sincere thanks to the Principal, Teachers and Friends of Malco Vidyalaya Matriculation Higher Secondary School, Mettur in providing the required help, resource and facility. Heartfelt appreciations to Dr.P.S.Jagadeeh Kumar, Stanford University, California for his motivation and inspiration to write this article. Sincere gratitude to our grandparents and mother Ms.J.Ruby for standing with us through the difficult moments.

\section{REFERENCES}

[1] P.S.Jagadeesh Kumar, R.Ramya. An efficient battery model for embedded systems, National conference on signal systems and communications, 7-8, May, 2008, Anna University, Chennai.

[2] P.T. Moseley and B.C. Tofield, Solid State Gas Sensors, IOP Publishing Ltd, Adam Hilger, 1987, Bristol UK.

[3] V. R. Katti, A. K. Debnath, K. P. Muthe, Manmeet Kaur, A. K. Dua, S. C. Gadkari, S. K. Gupta and V. C. Sahni, Sensors and Actuators B 96, 2003, 245.

[4] Garcia, E., Jimenez, M., De Santos, P., Armada, M. 2007. The Evolution of Robotics Research. Robotics \& Automation Magazine, IEEE, 14: 90-103.

[5] P.S.Jagadeesh Kumar. Accrue Discovery Regulation for Autonomous Robotic Control of Marine Cybernetics and Automation, International Journal of Communications on Applied Electronics (CAE), Vol. 5, No.1, May'2016, pp.37-41, Foundation of Computer Science FCS, New York, USA.

[6] Lund, H.H., Miglino O. From Simulated to Real Robots. Int. Conference on Evolutionary Computation, IEEE, 1996, pp. 362 - 365, Nagoya.

[7] Wayne, D.M. Fire Alarm System Research-Where it's been and where it's going. Fire Suppression \& Detection Research Application Symposium, 2006.

[8] P.S.Jagadeesh Kumar, Yanmin Yuan, Yang Yung, Mingmin Pan, Wenli Hu, 'Robotic Simulation of Human Brain Using Convolutional Deep Belief Networks', Int. Journal of Intelligent Machines and Robotics, 1 (2), pp. 180-191, 2018. 